\title{
Slit-lamp photography made easy by a spot metering system
}

\author{
P T KHAW AND A R ELKINGTON \\ From Southampton University, Southampton Eye Hospital
}

SUMmARY The use of a standard $35 \mathrm{~mm}$ camera with a spot metering system to take slit-lamp photographs is described. This system is mounted on a standard Haag-Streit slit-lamp and can be used with good results even by inexperienced operators.

Ophthalmology lends itself to photography. However, the cost of a dedicated slit-lamp camera and the technical difficulties involved deter many ophthalmologists from taking slit-lamp photographs. What is needed is a system that is (1) inexpensive; $(2)$ based on photographic apparatus readily available; (3) compatible with a standard slit-lamp; (4) as easy to use as a standard automatic camera, without any complicated settings.

A system has previously been described by Thaller ${ }^{1}$ that fulfils the first three of these criteria. His system consisted of a standard $35 \mathrm{~mm}$ camera and standard f 1.8 aperture lens mounted on a $\times 10$ Haag-Streit eyepiece by a simple adaptor. To take a photograph the camera and lens are mounted on the eyepiece, which is then inserted into the slit-lamp. Focusing is achieved by moving the slit-lamp backwards and forwards, and illumination is provided as usual by the slit-lamp light source.

However, this leaves the correct exposure to be determined by altering the speed of the shutter. The shutter speed can be extremely difficult to estimate, even after experience of several hundred photographs with this system. A small difference in slit width or lamp intensity can significantly alter the illumination. This necessitates taking three or more exposures to guarantee one acceptable photograph. The conventional centre weighted metering system of the standard camera cannot be used to automate this procedure. This is because the centre weighted system averages the illumination over the whole picture, whereas slit-lamp illumination varies considerably over the field of view.

Correspondence to Mr P T Khaw, FRCS, Moorfields Eye Hospital, City Road, London EC1V 2PD.
Table 1 Photographs that can be taken with the system

\begin{tabular}{|c|c|}
\hline Area & Notes \\
\hline $\begin{array}{l}\text { Conjunctiva/whole eye, } \\
\text { iris }\end{array}$ & $\begin{array}{l}\text { The whole eye can be photographed (wide } \\
\text { angle view) if a Hruby lens is used } \\
\text { between the slit-lamp and the eye }\end{array}$ \\
\hline Cornea: Section & $\begin{array}{l}\text { Take reading from centre of slit. To } \\
\text { achieve a picture with more than a slit of } \\
\text { light surrounded with darkness use the } \\
\text { overexposure facility (highlight) }\end{array}$ \\
\hline Whole & $\begin{array}{l}\text { Wide illumination beam and take } \\
\text { exposure reading off centre of picture }\end{array}$ \\
\hline Fluorescein & $\begin{array}{l}\text { Switch up the lamp voltage to } 7.5 \mathrm{~V} \text { or the } \\
\text { shutter speed will probably be too slow }\end{array}$ \\
\hline Endothelium & $\begin{array}{l}\text { Use endothelial contact lens. Try to angle } \\
\text { illumination so that reflections do not } \\
\text { enter the metering area or the } \\
\text { photograph will end up too dark }\end{array}$ \\
\hline Scleral illumination & $\begin{array}{l}\text { Decentre beam to illuminate sclera and } \\
\text { take reading from actual lesion, e.g., } \\
\text { corneal disciform scar }\end{array}$ \\
\hline Anterior chamber angle & $\begin{array}{l}\text { Use gonioscope normally and take } \\
\text { reading from part of picture required. } \\
\text { Again, try to avoid reflections into the } \\
\text { metered area }\end{array}$ \\
\hline Lens: Section/whole & Same technique as corneal section. \\
\hline Retroillumination & $\begin{array}{l}\text { Try to illuminate obliquely so that the } \\
\text { meter does not read directly from the } \\
\text { slit of light on the lens. The } \\
\text { overexposure facility (highlight) can be } \\
\text { used to ensure an adequately exposed } \\
\text { picture }\end{array}$ \\
\hline Fundus disc/post pole & $\begin{array}{l}\text { A Hruby lens, } 90 \text { dioptre lens, contact } \\
\text { lens, three-mirror lens, or } \\
\text { panfunduscope can be used. Some type } \\
\text { of reflection will always be present in } \\
\text { the picture, unlike a fundus camera. } \\
\text { However, good pictures can be } \\
\text { obtained. Again, oblique illumination } \\
\text { helps to avoid inaccurate metering and } \\
\text { excessive reflections in the photographs }\end{array}$ \\
\hline
\end{tabular}




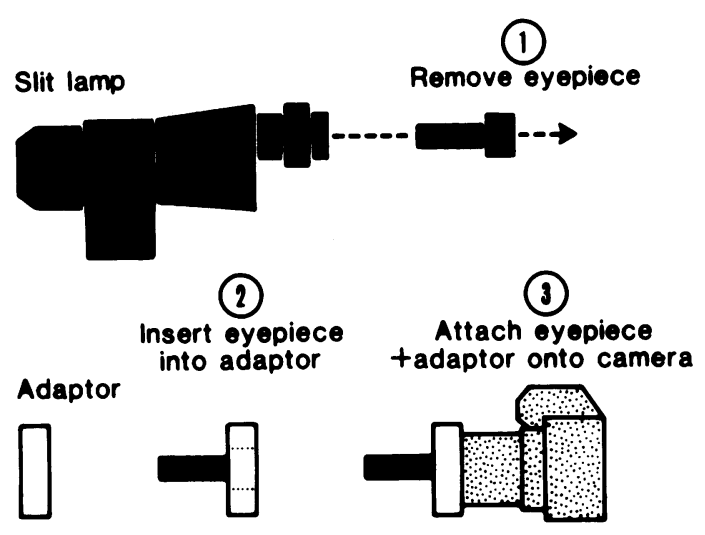

(4)

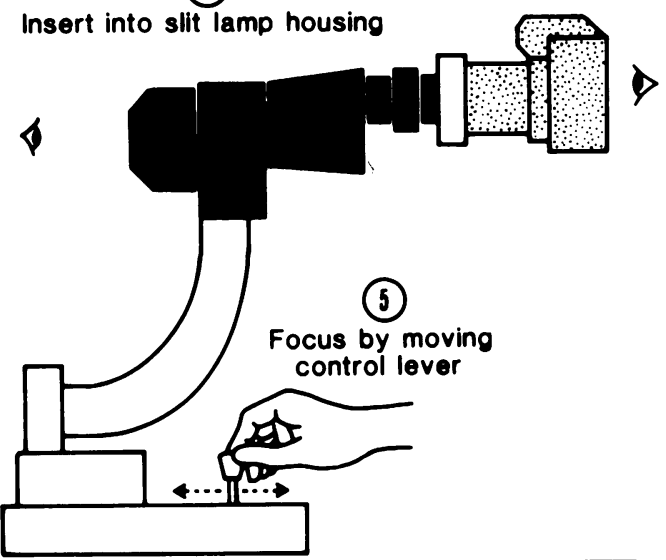

(1)

Position spot metering area over illuminated region
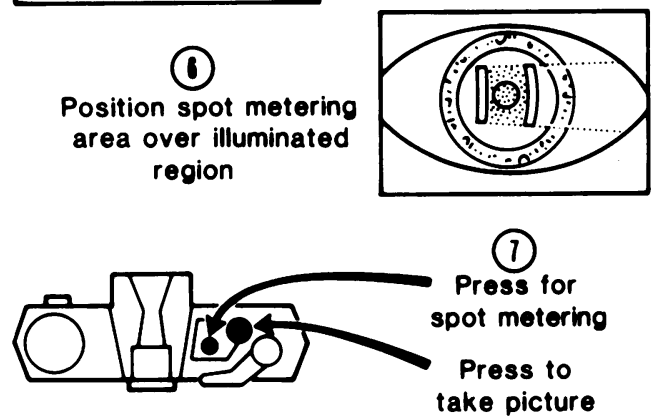

Fig. 1 Procedure for taking slit-lamp photographs with a standard $35 \mathrm{~mm}$ camera which has a spot metering facility.

Several cameras have recently become commercially available on the mass market which have a spot metering system. These take readings from the central $2 \%$ of the picture and base exposures on these readings. We used one of these cameras (Olympus OM-4) with a standard $f 1.8$ lens mounted on a HaagStreit slit-lamp. The procedure for taking photo-

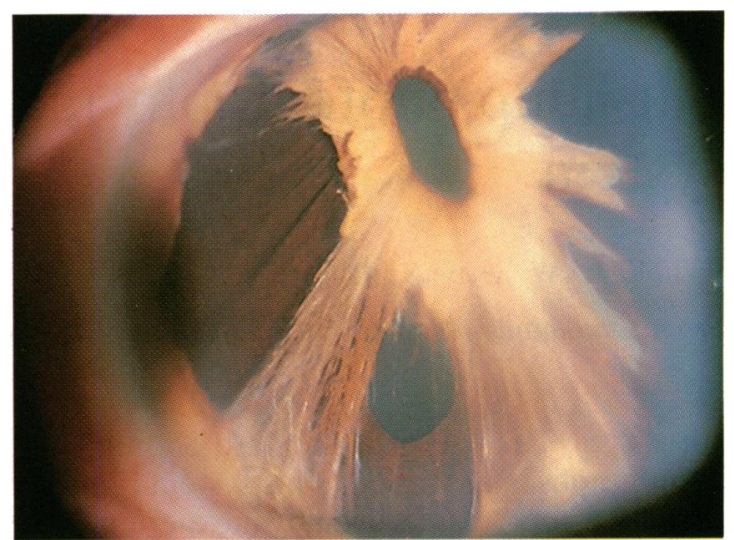

Fig. 2 Essential iris atrophy and mild corneal oedema. Photograph taken with spot metering at $\times 16$ magnification.

graphs was very simple (Fig. 1). The camera was used to photograph parts of the eye as shown in Table 1. Ophthalmologists with little or no photographic experience found the camera easy to use. They achieved acceptable results even at the first attempt.

The main problem with this system arises when relatively slow shutter speeds are sometimes necessary. This occurs particularly when blue light is used and when pictures are taken by retroillumination. This results in a blurred picture. If the intensity of the slit-lamp is switched up, the patient will not be able to tolerate the enhanced illumination. Initially Kodak Ektachrome Tungsten 160 ASA colour slide film was used, but the use of faster film such as 3M ASA 640 colour slide film helped to overcome many of these problems. Obviously even the most sophisticated metering system in existence cannot cope with all lighting conditions, but the spot metering system could cope with the majority of slit-lamp photographic conditions.

In summary, we are using a relatively inexpensive photographic system for slit-lamp photography that can be easily operated by ophthalmologists with little or no photographic experience. In addition, the camera purchased for this purpose (being a standard $35 \mathrm{~mm}$ camera) can also take excellent general photographs.

We thank Mr S Douglas of Olympus Optical Co. (London) for the loan of the OM-4 and Mr Peter Jack for his illustration.

Mr Khaw is in receipt of a 1986 Kodak bursary award.

Reference

1 Thaller VT. An inexpensive method of slit-lamp photography. $\mathrm{Br}$ J Ophthalmol 1983; 67: 63-6.

Accepted for publication 27 March 1987. 